\title{
As principais motivações elencadas para o desmame precoce por lactantes adultas: revisão integrativa da literatura
}

The main motivations listed for early weaning by adult breastfeeding women: integrative literature review

Las principales motivaciones enumeradas para el destete temprano de las mujeres adultas que amamantan: revisión integral de la literatura

Jucelia Santos Areia ${ }^{1}$, Tatiana Naiana Rodrigues dos Santos Porto ${ }^{1}$, Államy Danillo Moura e Silva ${ }^{1}$, Luciana Stanford Baldoino ${ }^{1 *}$, Rita de Cássia Rêgo de Araújo ${ }^{1}$, Vinícius de Sousa Martins ${ }^{1}$, Dorivaldo Pereira Carvalho ${ }^{1}$, Sônia Maria Leite Alcântara ${ }^{1}$, José Nilson Stanford Baldoino².

\section{RESUMO}

Objetivo: Analisar na literatura as principais motivações elencadas para o desmame precoce por lactantes adultas. Métodos: Trata-se de uma revisão integrativa. Os descritores utilizados encontram-se presentes no Banco de Descritores em Ciências da Saúde (DeCS) optou-se por: Desmame, aleitamento materno e mulher. A coleta de dados foi realizada em setembro de 2018, na Literatura Latino-Americana e do Caribe em Ciências da Saúde (LILACS), PubMed da National Library of Medicine National Institutes of Health dos EUA, Medical Literature Analysis and Retrieval System Online (MEDLINE), Banco de Dados em Enfermagem (BDENF) e Índice Bibliográfico Español en Ciencias de la Salud (IBECS). Resultados: Ao se analisar o perfil das publicações, o intervalo de 2014 a 2017 foram os anos onde ocorreram maior número de pesquisas da amostra (75\%). A abordagem metodológica em $50 \%$ dos artigos foi feita de forma ecológica e os demais, foram de coorte. Considerações finais: Os fatores relacionados a interrupção da amamentação de forma precoce estavam relacionados a fatores sociais, como estado civil, grau de escolaridade e idade; fatores físicos em como dor, intercorrências mamárias, hipolactia; ou fatores psiquiátricos como: a depressão pós parto.

Palavras-chave: Desmame Precoce, Aleitamento Materno, Mulher.

\begin{abstract}
Objective: Analyze in the literature the main motivations for early weaning by adult infants. Methods: This is an integrative review. The descriptors used are present in the Bank of Descriptors in Health Sciences (DeCS) this opted for weaning, breastfeeding and women. Data collection this was carried out in September 2018, in the Latin American and Caribbean Literature in Health Sciences (LILACS), PubMed of the National Library of Medicine of the USA, Medical Literature Analysis and Retrieval System Online (MEDLINE), Database of Nursing (BDENF) and Spanish Bibliographic Index in Health Sciences (IBECS). Results: When analyzing the profile of publications, the interval from 2014 to 2017 this was the year in which the largest number of surveys in the sample occurred (75\%). The methodological approach in $50 \%$ of the articles this was done in an ecological way and the others were cohort. Final considerations: Factors related to early termination of
\end{abstract}

\footnotetext{
${ }^{1}$ Faculdade de Ensino Superior Múltiplo-IESM, Timon-MA. *E-mail: Isbaldoino@hotmail.com

2 Universidade Católica de Pernambuco, Recife-PE.
} 
breastfeeding these were related to social factors, such as marital status, educational level and age; physical factors such as pain, breast complications, hypoacathy; or psychiatric factors such as: postpartum depression.

Keywords: Early Weaning, Breastfeeding, Woman.

\section{RESUMEN}

Objetivo: Analizar en la literatura las principales motivaciones enumeradas para el destete temprano de las mujeres adultas que amamantan. Métodos: Esta es una revisión integradora. Los descriptores utilizados están presentes en el Banco de Descriptores en Ciencias de la Salud (DeCS) optamos por: destete, lactancia y mujer. La recopilación de datos se realizó en Septiembre de 2018 en Literatura de Ciencias de la Salud de América Latina y el Caribe (LILACS), Pubmed de la Biblioteca Nacional de Medicina Institutos Nacionales de Salud, Sistema de Análisis y Recuperación de Literatura Médica en línea (MEDLINE), Banc de Datos de Enfermería (BDENF) e Índice Bibliográico Español en Ciencias de la Salud (IBECS). Resultados: Al analizar el perfil de las publicaciones, el intervalo ente 2014 y 2017 fueron los años com el mayor número de investigaciones en la amuestra (75\%). El enfoque metodológico en el 50\% de los artículos se realizó ecológicamente y los otros fueron de cohorte. Consideraciones finales: los factores relacionados com la interrupción temprana de la lactancia materna se relacionaron com factores sociales como el estado civil, el nivel educativo y la edad; factores físicos como dolor, complicaciones mamarias, hipolactia; fatores psiquiátricos como la depresión posparto.

Palabras-clave: Destete Temprano, Lactancia Materna, Mujer.

\section{INTRODUÇÃO}

Mesmo com as recomendações e com as medidas adotadas, o desmame de forma prematura, caracterizado pela interrupção e/ou abandono do aleitamento materno de forma exclusivo antes do bebê completar seis meses, independente dos motivos, ainda se mostra uma realidade frequente e indesejável (BARBOSA GEF, et al., 2017).

Barbosa GEF, et al. (2017) o posicionamento errado da mãe e/ou do bebê acaba dificultando o abocanhar correto do bebê em relação ao mamilo e que resulta no que denomina- se de "má pega". Esta, por sua vez, atrapalha na dinâmica da sucção e extração do leite materno, prejudicando o esvaziamento da mama e levando à uma queda da produção. Como resultado, a mãe introduz de forma precoce outros alimentos, resultando, assim, o desmame precoce.

Segundo Nascimento CS, et al., (2018), o ganho de peso, fatores relacionados a pega alterada, posicionamento alterado, fissura mamaria e ingurgitamento mamário e ainda o uso de alimentação artificial e hábitos considerados nocivos como uso de bicos e chupetas, águas e/ou chás, acabam por dificultar ainda mais a permanência da amamentação exclusiva.

No entanto, o ato de amamentar traz diversos benefícios tanto para a mãe como para a criança. Para a mulher a amamentação está relacionada com: sangramento menor no pós-parto, menor incidência de anemias, tem efeito contraceptivo por cerca de seis meses (aleitamento materno exclusivo (sem chupetas e/ou mamadeiras), combinado a amenorreia e intervalo máximo de horas entre as mamadas) e, consequente, maior intervalo interpartal, recuperação e perda mais rápida do peso pré-gestacional, além de menor prevalência de câncer de ovário, endométrio e mama. É estimado que o risco de desenvolvimento do câncer de mama na mulher que amamenta diminua em cerca de $4,3 \%$ a cada 12 meses de amamentação (BRASIL, 2015).

A amamentação beneficia a saúde da mulher, realizando a involução uterina de forma mais rápida e como consequência, reduz o sangramento pós-parto, as chances do câncer de mama e de ovário e aumenta o espaçamento entre as gestações, isto, se a mulher ainda não menstruou e amamenta o bebê exclusivamente 
até os seis meses de idade. A amamentação facilita a reconstituição dos minerais no organismo da mulher, prevenindo fraturas vertebrais e do fêmur no período da menopausa (NASCIMENTO CS, et al., 2018).

Vale ressaltar que $O$ ato da amamentação representa muito mais que apenas nutrir a criança. É um processo complexo que envolve uma profunda interação entre mãe e filho, com repercussões importantes no estado nutricional da criança, na habilidade do organismo em se defender de infecções, em sua fisiologia e principalmente no seu desenvolvimento cognitivo e emocional. Para a criança, os benefícios estão relacionados a: Redução da mortalidade na infância; Proteção contra diarreia, infecções respiratórias, alergias, hipertensão, hipercolesterolemia, diabetes e obesidade. O Ministério da Saúde adota as definições de Aleitamento Materno que são preconizadas pela OMS. (BRASIL, 2015). (Tabela 1).

Apesar dos inúmeros benefícios já conhecidos e amplamente divulgados do aleitamento materno (AM) e da criação de programas de incentivo a essa prática, as taxas mundiais de amamentação ainda permanecem abaixo dos níveis recomendados. Aumentar a taxa de amamentação exclusiva e a duração mediana de aleitamento materno tem sido um desafio no mundo e, em especial, no Brasil (ROCCI ER e FERNANDES RAQ, 2014).

O desmame precoce é um grande problema de saúde pública, devido a questões culturais, sociais, escolaridade, idade, ausência de um companheiro e falta de conhecimento que a mãe e família têm sobre os benefícios que o leite materno traz. A falta de orientação de profissionais de saúde e, assim, fazendo com que as mães acreditem que seu leite não é o suficiente, introduzindo leite artificial, relatando também desgaste, dor nos peitos e cansaço devido ao despreparo da mesma (COUTINHO SE e KAISAR DE, 2015).

Diante da importância da amamentação nos anos iniciais da vida da criança e por essa estar relacionada com boa perspectiva na saúde dessas crianças. É imprescindível que as motivações para a interrupção precoce desta prática sejam estudadas, buscando sempre amenizá-los para que a amamentação seja mantida pelo maior período de tempo. Com isso o objetivo deste estudo é analisar na literatura, as principais motivações elencadas para o desmame precoce por lactantes adultas.

\section{MÉTODOS}

Trata-se de uma revisão integrativa. Para Santos CMC, et. al. (2007) uma boa estratégia para construir a questão de pesquisa, sendo de natureza diversa, oriunda da clínica, da gestão de recursos humanos e materiais, da busca de instrumentos para avaliação de sintomas, dentre os principais é a estratégia PICO. A questão de pesquisa adequada (bem construída) permite que a definição correta, da qual as informações (evidências) são necessárias para a solução do aspecto clínico da investigação, maximize a recuperação de evidências nas bases de dados, focar o propósito da investigação e evitar buscas desnecessárias.

A questão de pesquisa foi organizada de acordo com a estratégia PICO (P: População; I: Intervenção; C: Comparação; O: Desfecho). Portanto, foi sintetizada a seguinte estrutura: P - Lactantes; I - Amamentação; C - Sem comparação; O - Desmame precoce. Por tanto, a questão norteadora é "Quais evidencias disponíveis na literatura sobre as motivações para o desmame precoce em lactantes adultas?

Os descritores utilizados encontram-se presentes no Bando de Descritores em Ciências da Saúde (DeCS) e baseada na questão supraproposta, optou-se por: desmame, aleitamento materno e mulher. Os descritores não controlados (Palavras-chave) usados foram: Aleitamento, Amamentação, Alimentação ao Peito, Desmame precoce. Como forma de metodificar a coleta da amostragem, utilizou os operadores boleanos "AND", para conectar os descritores, e "OR" para conectar as palavras-chave.

Para o banco de dados internacionais optou-se pela utilização de termos MESH, estão em conformidade com a plataforma, foram eles: "weaning", "Breast feeding" e "women". A coleta de dados foi realizada em setembro de 2018, na Literatura Latino-Americana e do Caribe em Ciências da Saúde (LILACS), PubMed da National Library of Medicine National Institutes of Health dos EUA, Medical Literature Analysis and Retrieval System Online (MEDLINE), Banco de Dados em Enfermagem (BDENF) e Índice Bibliográfico Español en Ciencias de la Salud (IBECS). 
De acordo com a pergunta norteadora e interesse da pesquisadora, foram analisados os conteúdos abordados em cada artigo, para assim os trabalhos serem comparados e agrupados por similaridade de conteúdo. Os critérios de inclusão escolhidos foram: Artigos que estivessem em conformidade com a questão norteadora do estudo; publicados nos últimos cinco anos (2013-2018), estarem disponíveis na íntegra. Foram excluídos estudos secundários ou cartas ao editor, anais de eventos científicos, tese, dissertações e estudos duplicados. Após a aplicação dos critérios restaram cinco artigos para análise provenientes da LILACS, um da PUBMED e um da BDENF, conforme demonstrado (Figura 1).

Figura 1 - Fluxograma da abordagem metodológica usada.

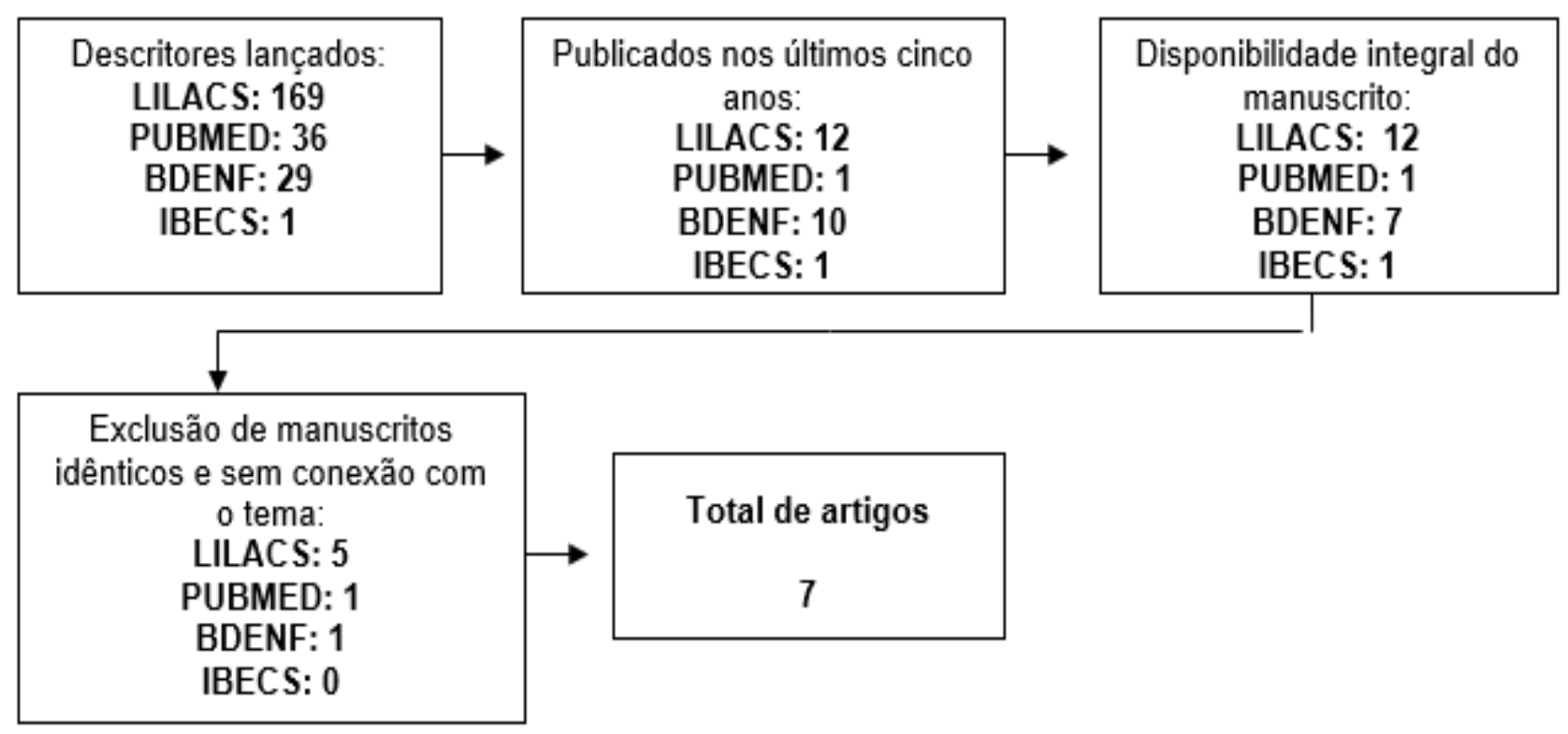

Fonte: Porto TNRS et al., 2019.

A coleta de informações relacionadas ao estudo foi feita pela aplicação de instrumento contendo: autores, país de origem, ano de publicação, periódico, amostra, delineamento do estudo, nível de evidência. Este último, por sua vez, é determinado por Oxford Center for Evidence-based Medicine, onde consta classificação baseada na abordagem metodológica.

Dessa forma, é pertinente enfocar que a avaliação dos artigos foi guiada pela verificação criteriosa dos estudos selecionados a partir dos dados obtidos durante a categorização das amostras e, que contemplavam a questão norteadora deste trabalho. Para melhor entendimento do seguimento metodológico utilizado para esta avaliação, foram elaboradas tabelas que representam os resultados obtidos contendo a descrição das amostras.

Assim, optou-se, neste contexto, pela exibição dos dados considerando os elementos de cada artigo dispostos de forma individualizada, partindo dos achados sobre a identificação da publicação e delineamento do método empenhado em sua elaboração.

\section{RESULTADOS E DISCUSSÃO}

A amostra foi composta por sete artigos. Ao se analisar o perfil das publicações, como forma de responder o segundo objetivo específico proposto notou-se que, o intervalo de 2014 a 2017 foram os anosonde ocorreram maior número de pesquisas da amostra (75\%). A abordagem metodológica em $50 \%$ dos artigos foi feita de forma ecológica e os demais, foram de coorte. O quadro-síntese dos artigos incluídos no estudo elenca pontos cruciais no entendimento destes conforme mostra (Quadro 1). 
Quadro 1 - Quadro-síntese das características dos estudos incluídos na revisão - Timon, MA, Brasil, 2019.

\begin{tabular}{|c|c|c|c|c|}
\hline Autores (Ano) & Periódicos / País & $\begin{array}{c}\text { Amostra/ Tipo de } \\
\text { estudo }\end{array}$ & $\begin{array}{l}\text { Motivações para } \\
\text { desmame }\end{array}$ & N.E \\
\hline $\begin{array}{l}\text { Siqueira FPC, et } \\
\text { al. (2017) }\end{array}$ & $\begin{array}{l}\text { Revista enfermagem } \\
\text { pernambucana/ Brasil }\end{array}$ & $\begin{array}{l}25 \text { puérperas / } \\
\text { Estudo Ecológico }\end{array}$ & $\begin{array}{c}\text { Falta de apoio, falta de } \\
\text { empoderamento da } \\
\text { mulher. }\end{array}$ & $2 \mathrm{C}$ \\
\hline $\begin{array}{l}\text { Díaz-Gomez NM, } \\
\text { et al. (2016) }\end{array}$ & $\begin{array}{c}\text { Revista Espanhola } \\
\text { Salud Publica/ } \\
\text { Espanha }\end{array}$ & $\begin{array}{l}569 \text { Mães / estudo } \\
\text { Coorte }\end{array}$ & $\begin{array}{l}\text { Pouco Leite, trabalho, } \\
\text { espaço público, despertar } \\
\text { pela madrugada. }\end{array}$ & $2 \mathrm{~B}$ \\
\hline $\begin{array}{l}\text { Barbieri MC, et } \\
\text { al. (2015) }\end{array}$ & $\begin{array}{c}\text { Semina: Ciências } \\
\text { Biológicas e da saúde/ } \\
\text { Brasil }\end{array}$ & $\begin{array}{l}36 \text { Mães/ Estudo } \\
\text { Ecológico }\end{array}$ & $\begin{array}{l}\text { Término da licença } \\
\text { maternidade; Volta ao } \\
\text { trabalho; Orientação } \\
\text { médica; Problemas com a } \\
\text { mama; vontade. }\end{array}$ & $2 \mathrm{C}$ \\
\hline $\begin{array}{l}\text { Machado MCM, } \\
\text { et al. (2014) }\end{array}$ & $\begin{array}{l}\text { Revista Saúde } \\
\text { Pública/ Brasil }\end{array}$ & $\begin{array}{l}168 \text { mães/ Estudo } \\
\text { de coorte }\end{array}$ & $\begin{array}{c}\text { Depressão e parto } \\
\text { traumático, retorno ao } \\
\text { trabalho. }\end{array}$ & $2 \mathrm{~B}$ \\
\hline $\begin{array}{c}\text { Torres LEAS, et } \\
\text { al. (2014) }\end{array}$ & $\begin{array}{l}\text { Espaço Saúde } \\
\text { (Online) / Brasil }\end{array}$ & $\begin{array}{l}\text { Mães da estratégia } \\
\text { saúde da família/ } \\
\text { Estudo Ecológico }\end{array}$ & $\begin{array}{l}\text { Falta de apoio familiar, } \\
\text { fissuras mamárias. }\end{array}$ & $2 \mathrm{C}$ \\
\hline $\begin{array}{c}\text { Altamimi E, et al. } \\
(2017)\end{array}$ & $\begin{array}{l}\text { Saúde no local de } \\
\text { trabalho / Jordânia }\end{array}$ & $\begin{array}{l}400 \text { mães/ Estudo } \\
\text { ecológico }\end{array}$ & Trabalho. & $2 \mathrm{C}$ \\
\hline $\begin{array}{l}\text { Paula N, et al. } \\
\qquad(2015)\end{array}$ & $\begin{array}{l}\text { Revista Eletrônica } \\
\text { Enfermagem }\end{array}$ & $\begin{array}{c}9 \text { famílias/ Estudo } \\
\text { Ecológico }\end{array}$ & $\begin{array}{l}\text { Desconhecimento do } \\
\text { parceiro quanto a } \\
\text { importância do } \\
\text { aleitamento }\end{array}$ & $2 \mathrm{C}$ \\
\hline
\end{tabular}

Fonte: Porto TNRS, et al., 2019.

Alguns fatores sociais se mostram de risco para o desmame precoce em mulheres adultas, segundo os estudos analisados, o retorno ao trabalho ou estudos, cultura, grau de escolaridade e estado civil foram apontados. No entanto, é importante salientar que o retorno ao trabalho e aos estudos correspondem a 50\% dos fatores sociais apontados no estudo (Gráfico 1).

Gráfico 1 - Análise das motivações para interrupção da amamentação relacionadas a fatores sociais.

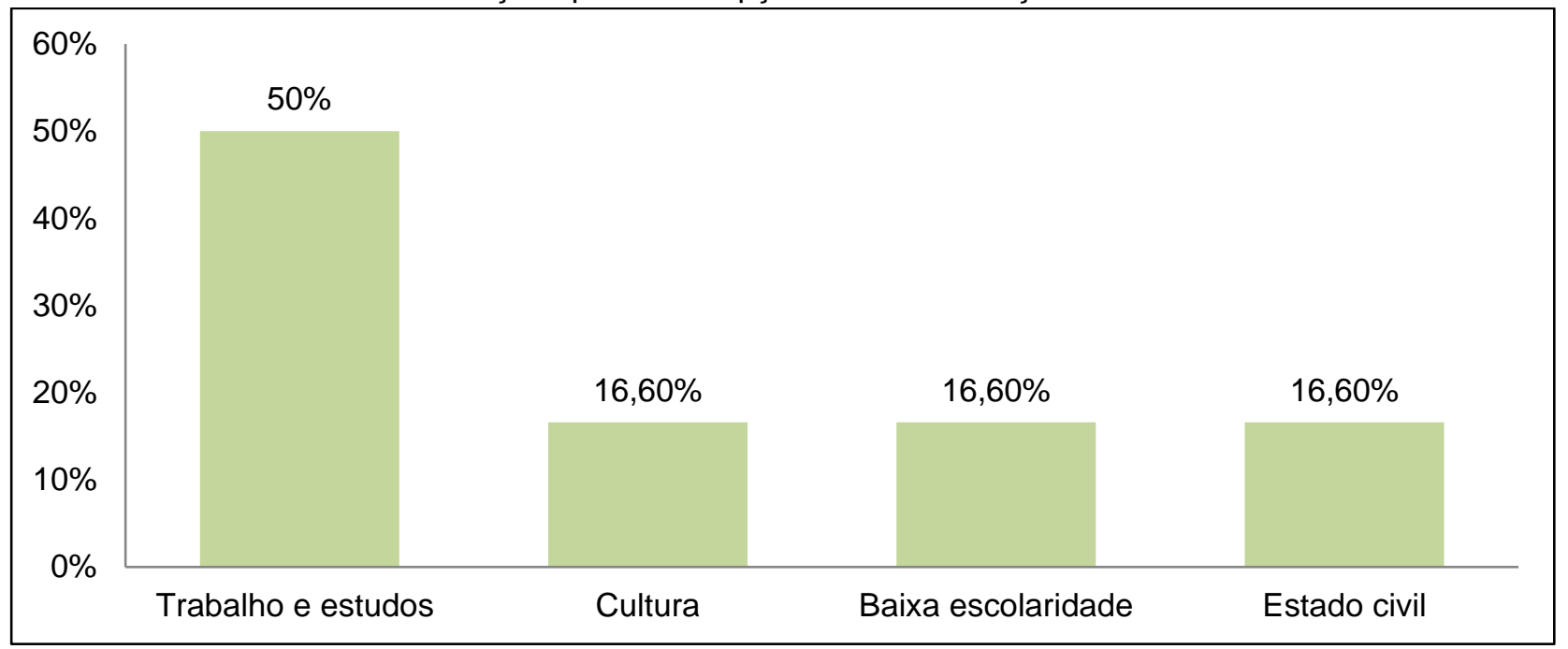

Fonte: Porto TNRS, et al., 2019. 
O trabalho é fator determinante na interrupção da amamentação precocemente. Portanto, este aparece como um fator que interfere diretamente na efetividade do aleitamento materno. $O$ fato de as mulheres precisarem exercer suas atividades longe de suas residências e enfrentarem rígidas jornadas de trabalho e pouca flexibilidade de horário acaba dificultando a manutenção do aleitamento materno (ALTAMIMI E, et al., 2017).

O trabalho quando em consonância com as normas trabalhistas assegura o período de no máximo seis meses de benefícios a mães que possuem carteira de trabalho assinada ou aquelas que realizam contribuição de benefício por pelo menos dez meses. Em contrapartida, algumas destas trabalhadoras informais por não possuírem carteira assinada e não contribuírem com a Previdência Social, elas não têm direito à licençamaternidade e ao salário maternidade, o que lhes demanda retornar precocemente ao trabalho, considerando que são provedoras do lar ou precisam trabalhar para complementar a renda familiar (RIBEIRO KV, et al., 2017).

Considerando a cronologia cultural desde a época colonial houve grande mudança. Até o século XIX, o aleitamento ganha conotação de problema nacional, resultado do receituário higienista. Até então, as mulheres permaneciam seguindo os costumes coloniais de não amamentarem seus filhos, comportamento que começa se a contrapor aos interesses políticos populacionistas da elite agrária da época e passa a ser considerado, no discurso higiênico, como uma infração às leis da natureza (KALIL IR e COSTA MC, 2016).

Hoje, o ambiente doméstico a decisão de amamentar é influenciada pela história familiar das mulheres, ou seja, conforme a vivência da amamentação na família. Neste sentido, presume-se que este contexto poderá Ihes proporcionar experiências positivas, portanto, a cultura capitalista moderna, tende a incentivar 0 aleitamento materno em mães adultas, no estando, aquelas adolescentes são motivadas a não realizar $\mathrm{o}$ ato (CREMONESE LS, et al., 2016).

A família é a unidade básica na cultura, importante no sentido de compartilhar a vivência e os sentimentos que envolvem o processo de amamentar. É possível perceber a dualidade da influência de familiares na amamentação, tanto de forma positiva, como contrária, em que na maioria das vezes, são os mais velhos, como mãe e avó, que influenciam na hora da amamentação, assim o cuidado do filho é um ensinamento que passa de geração para geração (WILHELM LA, et al., 2016).

A decisão materna de não amamentar, por vezes, é construída e determinada antes mesmo do nascimento do filho, fundamentada em crenças pessoais e culturais de ser um processo que causa prejuízos estéticos à mãe. Essas crenças podem ser construídas por meio de influências de relatos de outras mães da sua rede de sociabilidade ou observações e de sentimentos gerados ao longo da gestação, parto e puerpério sobre a dor, o desconforto, o cansaço e sobre as consequências e mudanças no corpo materno durante e após a amamentação (URBANETTO PDG, et al., 2018).

Para Cremonese LS, et al. (2016) todas as formas de amamentação necessitam de uma boa técnica para que aconteça de forma eficaz, sem prejuízo para nenhum dos envolvidos. Apesar de a sucção do recémnascido ser um ato reflexo, ele precisa aprender a retirar o leite do peito de forma eficiente. Quando o bebê pega a mama adequadamente o que requer uma abertura ampla da boca, abocanhando não apenas o mamilo, mas também parte da aréola forma-se um lacre perfeito entre a boca e a mama, garantindo a formação do vácuo, indispensável para que o mamilo e a aréola se mantenham dentro da boca do bebê.

O desmame precoce é um processo multifatorial, estando alguns fatores relacionados a distúrbios físicos, por meio da análise dos artigos que compõe a amostra, foram enumerados os seguintes: Dor, Intercorrências mamárias, Rejeição do bebê, Gravidez, Reduzida produção de leite, conforme mostrado (Gráfico 2). 
Gráfico 2 - Análise de influências de distúrbios físicos relacionados ao desmame precoce.

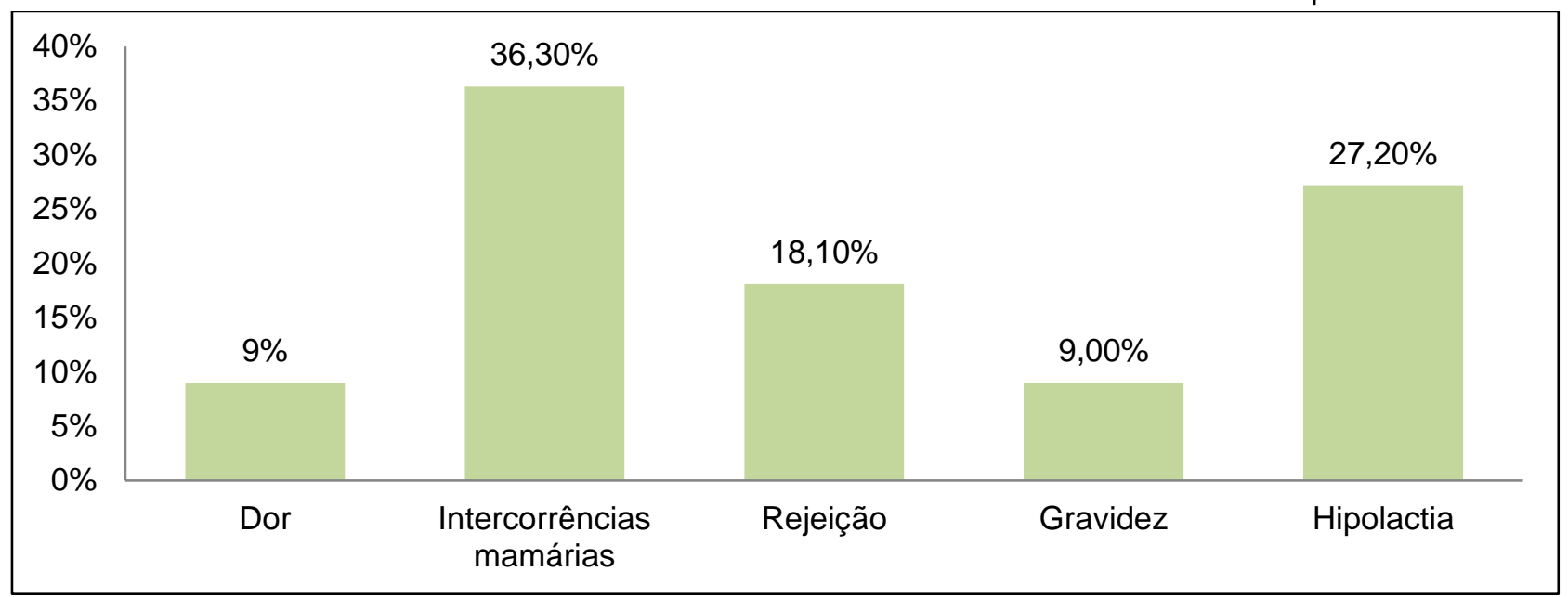

Fonte: Porto TNRS, et al., 2019.

Em se tratando de intercorrências mamárias têm início, especialmente, nos primeiros dias, aproximadamente entre o primeiro e décimo quinto dia após o parto. Os fatores clínicos que interferem no aleitamento materno, incluindo processos dolorosos, fissuras mamárias, ingurgitamento e mastite. Nos primeiros dias do puerpério, as mães passam por desordens psicológicas que contribuem para a dor ao amamentar e, caso essa dor permaneça em todas as mamadas, contribuirá para o desmame precoce. Quanto mais rápido identificar os sinais clínicos mais simples, menor é a probabilidade de um problema maior como a mastite (SIQUEIRA FPC, et al., 2017).

A prática de amamentar é uma experiência que envolve uma série de fatores maternos e outros relacionados ao Recém Nascido (RN). Dentre esses fatores destacam-se as intercorrências mamárias, que têm início, especialmente, nos primeiros dias, aproximadamente entre o primeiro e décimo quinto dia após o parto. As intercorrências mais comuns são ingurgitamento e fissura mamária (MATTOS MP, et al., 2016).

A hipolactia foi citada como fator que interfere na manutenção da amamentação. Geralmente há essa crença pela mãe por não sentir as mamas cheias, bem como a produção do leite reduzida nos primeiros dias, que é um período de adaptação no corpo, o que a deixa preocupada e temerosa quanto à sua capacidade para produzir o volume de leite adequado para o crescimento e ganho de peso da criança (AMARAL LJX, et al., 2015).

Para Diáz-Gómez NM, et al. (2016) os principais motivos para o desmame foi a incorporação imediata ao trabalho $(33,8 \%)$, seguido da falta de recomendações dos profissionais de saúde $(32,4 \%)$ e problemas de saúde do bebê e da mãe $(14,8 \%)$. Já quando indagadas sobre quem teve maior influência em sua decisão de amamentar, 67,5\% disseram que foi uma decisão própria, 26,5\% disse que a família e 15,2\% disseram seguir as orientações do pediatra.

Segundo Barbosa GEF, et al. (2017) a depressão pós-parto é um dos principais distúrbios psíquicos que acabam por impedir que a mãe prolongue 0 ato de amamentar seu filho. Outro ponto que também foi mencionado nos artigos estudados foi a vivência de um parto traumático.

Sobre a depressão pós-parto (DPP), existe uma multifatoriedade relacionada a estes casos, são eles, gravidez não desejada, baixo peso do bebê, alimentação do bebê direto na mamadeira, pouca idade da mãe, mãe solteira, desemprego do conjugue, múltiplos filhos, desemprego após licença, luto, separação do casal durante a gravidez, antecedentes psiquiátricos anteriores ou durante a gravidez e problemas na tireoide (SANTOS GMR, et al., 2016).

O termo DPP é usado para designar qualquer episódio depressivo que ocorra nos meses que se seguem ao nascimento do bebê, havendo estudos que consideram dois meses, três meses, seis meses, e até um ano. Geralmente, ocorrem humor deprimido, perda de prazer e interesse nas atividades, alteração de peso 
e/ou apetite, alteração de sono, agitação ou retardo psicomotor, sensação de fadiga, sentimento de inutilidade ou culpa, dificuldade para concentrar-se ou tomar decisões e até pensamentos de morte ou suicídio (MACHADO MCM, et al., 2014).

Com relação aos traumas vividos no parto, geralmente está relacionado a casos de violência obstétricas. Esta é definida como toda negligência durante a assistência por meio de discriminação social, violência verbal (tratamento grosseiro, piadas de mal gosto, frases ofensivas, repreensões durante as contrações, humilhação intencional) e violência física (não utilização de medicação analgésica quando indicada), levando até mesmo ao abuso sexual. $O$ uso inadequado de tecnologias, procedimentos desnecessários frente às evidências científicas, resultando em uma cascata de intervenções com riscos e sequelas em potencial, também pode ser considerado como prática violenta (SENA LM e TESSER CD, 2016).

No cotidiano desse processo, os fatores físicos, portanto, tendem a aderir ao aleitamento misto de forma mais precoce, o aleitamento misto, ou seja, já são introduzidos chás ou leite industrializado quando há acometimento de limitações físicas na mãe. Em questionamento, elas alegaram que seus bebês choravam muito, e por conselhos da família introduziram outro alimento além do peito materno (SANTOS GMR, et al., 2016).

\section{CONSIDERAÇÕES FINAIS}

Os resultados evidenciados pelo estudo apontam possibilidades de visualizar o cenário que cerca a problemática do desmame precoce, bem como atender o objetivo proposto na pesquisa. Esses mostram que apesar de serem do conhecimento comum a importância do leite no desenvolvimento das crianças, outros fatores acabam interferindo neste processo como: sociais, físicos e psicológicos mercado de trabalho, a depressão pós-parto, entre outros. Entretanto, mesmo que muitos dos fatores expostos neste estudo pareçam esclarecer as causas do desmame precoce, como: dificuldades relacionadas à pouca produção de leite ou "leite fraco", problemas nas mamas e a rejeição do bebê em pegar a mama, o aumento da participação feminina no mercado de trabalho, a depressão pós-parto, entre outros. É aceitável deduzir outros motivos que induzam ao abandono do ato de amamentar, sendo estas, ligadas a questões sociais, à relação com o companheiro e a família, às influências culturais e à sua resposta aos diversos problemas do dia-a-dia.

\section{REFERÊNCIAS}

1. ALtAMIMI E, et al. Knowledge, Attitude, and Practice of Breastfeeding Among Working Mothers in South Jordan. Workplace Health \& Safety, 2017; 65(5): 210-218.

2. AMARAL LJX, et al. Fatores que influenciam na interrupção do aleitamento materno exclusivo em nutrizes. Rev. Gaúcha Enferm, 2015; 36(spe): 127-134.

3. BARBOSA GEF, et al. Dificuldades Iniciais com a Técnica da Amamentação e Fatores Associados a Problemas com a Mama em Puérperas. Rev Paul de Pediatr, 2017; 35(3): 213-220.

4. BRASIL MS. Aleitamento Materno e Alimentação Complementar. Brasília, Ministério da Saúde, 2015.

5. CREMONESE LS, et al. A decisão de amamentar durante a adolescência: um estudo na perspectiva cultural. Rev de Enf da UFSM, 2016; 6(3): 317- 326.

6. COUTINHO SE, KAISER DE. Visão da enfermagem sobre o aleitamento materno em uma unidade de internação neonatal: relato de experiência. Boletim Científico de Pediatria, 2015; 4(1): 11.

7. DÍAZ-GÓMEZ NM, et al. Motivaciones y barreras percibidas por mujeres españolas en relación a la lactancia materna. Rev Esp Salud Pública, 2016; 90(15): 1-18.

8. KALIL IR, COSTA MC. "Nada mais natural que amamentar" Discursos contemporâneos sobre aleitamento materno no Brasil. Rev Eletrônica Comunic Informação Saúde, 2016; 6(4): 11-15.

9. MACHADO MCM, et. al. Determinantes of the exclusive breastfeeding abandin psychococial Factors. 2014; 46(6): 33-5.

10. MATTOS MP, et al. Intercorrências Mamárias Relacionadas Com A Amamentação: Uma Revisão Sistemática. Rev Cien Saúde Baiana, 2016; 1(1): 22-25.

11. NASCIMENTO CS, et al. Dificuldades iniciais de amamentação na população atendida no ambulatório de amamentação do Hospital Universitário Júlio Müller. Rev coorte, 2018; 7(1): 123-132. 
12. POMPEO DA, et al. Revisão integrativa: etapa inicial do processo de validação de diagnóstico de enfermagem. Acta Paul. Enf, 2009; 22(4): 222-232.

13. ROCCI ES, FERNANDES RAQ. Dificuldades no aleitamento materno e influência no desmame precoce. Rev Bras enferm, 2014; 67(1): 22-27.

14. RIBEIRO KV, et al. A amamentação e o trabalho informal: a vivência de mães trabalhadoras.RevUniver, 2017; 8(2): 3-9.

15. SANTOS CMC. Estrategia PICO para la construcción de la pregunta de investigacióny labús que da de evidencias. Rev Latino-am. Enfermagem. 2007; 15(3): 12-3.

16. SANTOS GMR, et al. Mitos e crenças sobre aleitamento materno que levam ao desmame precoce nas estratégias saúde da família no município de Firminópolis-GO. Rev. Eletr. Faculdade Montes Belos, 2016; 8(4): 10-1.

17. SENA LM, TESSER CD. Violência obstétrica no Brasil e o ciberativismo de mulheres mães: relato de duas experiências. Inter Comunic Saúde Educ, 2016; 21(1): 209-220.

18. SIQUEIRA FPC, et al. Percepção da Mulher quanto à influência das avós no processo de amamentação. Rev enferm UFPE online, 2017; 11 (supl): 2565-75.

19. URBANETTO PDG, et al. Facilidades e dificuldades encontradas pelas puérperas para amamentar. Rev Cuidado é Fundamental Online, 2018; 10(2): 399-405.

20. WILHELM LA, et al. A vivência da amamentação na ótica de mulheres: contribuições para a enfermagem. Rev de Enferm da UFSM, 2015; 5(1): 160-8. 